\title{
TRABALHO E EDUCAÇÃO: O PROCESSO DA EXISTÊNCIA HUMANA
}

\author{
WORK AND EDUCATION: THE PROCESS OF HUMAN EXISTENCE
}

\section{TRABAJO Y EDUCACIÓN: EL PROCESO DE EXISTENCIA HUMANA}

DOI: http://dx.doi.org/10.9771/gmed.v11i3.34929

\begin{abstract}
Vanderlei Amboni1
Resumo: Este texto apresenta o trabalho como mediação entre o hominídeo e a natureza no processo de hominização e materialidade do homem e, como consequência, a humanização do ser social homem no seu devir histórico. Para tanto, partimos da premissa sob a qual só há ser histórico nos limites de trabalho, cuja materialidade dá forma aos objetos e ao próprio homem. Neste sentido, o ato de comer, beber, vestir-se e abrigar-se torna-se ato contínuo à vida material, na qual o homem necessita realizar diuturnamente para sua reprodução biológica e social. Para darmos conta do nosso objeto, serão analisadas as obras de autores materialistas, para quem o mundo humano é criação das relações mediadas pelo trabalho entre homem e natureza. Ao criar o mundo humano, os homens criam também formas de produzir sua vida material mediada pelas condições reais de sua existência, cuja expressão social se forma nas relações sociais de produção, determinando o caráter efêmero das determinadas formações históricas de produção que o homem criou ao longo de sua existência material.
\end{abstract}

Palavras-chave: Trabalho. Educação. Hominização. Formação social.

Abstract: This text presents the work as a mediation between the hominid and the nature in the process of hominization and materiality of man and, as a consequence, the humanization of the social man in his historical becoming. For this, we start from the premise that there is only historical in the limits of work, whose materiality gives shape to objects and to man himself. In this sense, the act of eating, drinking, dressing and sheltering becomes a continuous act to material life, in which man needs to perform daily for his biological and social reproduction. In order to realize our object, we will analyze the works of materialistic authors, for whom the human world is the creation of relations mediated by the work between man and nature. In creating the human world, men also create ways of producing their material life mediated by the actual conditions of their existence, whose social expression is formed in the social relations of production, determining the ephemeral character of the certain historical formations of production which man created by throughout its material existence.

Keywords: Work, Education, Hominization, Social formation.

Resumen: Este texto presenta el trabajo como una mediación entre el homínido y la naturaleza en el proceso de hominización y materialidad del hombre y, como consecuencia, la humanización del hombre social en su devenir histórico. Para esto, partimos de la premisa de que solo existe un límite histórico en el trabajo, cuya materialidad da forma a los objetos y al hombre mismo. En este sentido, el acto de comer, beber, vestirse y refugiarse se convierte en un acto continuo para la vida material, en el cual el hombre necesita actuar diariamente para su reproducción biológica y social. Para realizar nuestro objeto, analizaremos las obras de autores materialistas, para quienes el mundo humano es la creación de relaciones mediadas por el trabajo entre el hombre y la naturaleza. Al crear el mundo humano, los hombres también crean formas de producir su vida material mediada por las condiciones reales de su existencia, cuya expresión social se forma en las relaciones sociales de producción, determinando el carácter efímero de ciertas formaciones históricas de producción que el hombre creó por a lo largo de su existencia material.

Palabras clave: Trabajo. Educación. Hominización. Formación social.

\section{Introdução}

Neste trabalho pretendemos analisar o processo fundante do ser social, cujo primado e essência da vida social do homem é o trabalho. E o que é trabalho? O trabalho, portanto, é o ato sob o qual o homem 
transforma a natureza se adaptando a ela e, ao mesmo tempo, adapta a natureza a si mesmo como meio de reprodução social. Neste processo, a base real desse movimento dialético “[...] são os indivíduos reais, a sua acção e as suas condições materiais de existência, quer se trate daquelas que encontrou já elaboradas quando do seu aparecimento das que ele próprio criou. [...]” (MARX; ENGELS, 1980, p. 18). No longo processo do devir do homem, na sua relação com determinada natureza, ele cria relações sociais distintas entre si, que dão formas sociais de produção e de organização da vida social. Com isso, afirma-se o primado do trabalho na materialidade da vida do homem, que cria, no ambiente natural, o mundo humano. Nesta perspectiva, as premissas materialistas da qual partimos é o indivíduo real e as condições dadas pelo ambiente natural na sua luta pela vida, o que leva o indivíduo ao afastamento da barreira natural como elo de sobrevivência, o qual passa a produzir suas próprias condições de reprodução, dentre elas o ato de comer, beber, vestir-se e abrigar-se como práxis humana por meio de trabalho. Isso leva Lukács a afirmar que " [...] a essência do trabalho humano consiste no fato de que, em primeiro lugar, ele nasce em meio à luta pela existência e, em segundo lugar, todos os seus estágios são produtos de sua autoatividade" (LUKÁCS, 2013, p. 43), ou seja, nasce e permanece como uma atividade do homem e a "atividade é um processo de intertráfico entre pólos opostos, sujeito e objeto" (LIONTIEV, 1972, p. 02). Também é significativo a posição de Paro, para quem “o trabalho em sua forma humana é, [...] a mediação que o homem necessita para construir-se historicamente" (PARO, 1999, 106). Dessa forma, "trata-se de aprender que o ser humano como ser natural - necessita elaborar a natureza, transformá-la, e pelo trabalho extrair dela bens úteis para satisfazer suas necessidades vitais e socioculturais” (FRIGOTTO, 2010, p. 20).

$\mathrm{Na}$ perspectiva do trabalho como sinônimo de hominização/humanização, Foladori et all sustentam que "é fato aceito pela maioria dos antropólogos que o homem se diferenciou dos animais pelo trabalho acumulado" e que "a fabricação de ferramentas pelo homem (man a tool maker) e as diferentes técnicas utilizadas são os principais critérios dos arqueólogos para distinguir as etapas da pré-história da humanidade" e o "trabalho como atividade consciente da transformação requer o uso de meios de trabalho e se aplica sobre um objeto". Neste sentido, a "peculiaridade do ser humano é ter aprendido a acumular estes meios através do tempo, aperfeiçoando-os e permitindo o incremento progressivo da produtividade do trabalho", e reafirmam que o postulado do trabalho é o que "diferencia o ser humano dos outros animais, que não acumulam este tipo de informação, repetindo a cada geração o mesmo comportamento com a natureza externa" (FOLADORI et all, 2016, p. 15). Neste processo, "o controle do fogo foi, presumidamente, o primeiro grande passo na emancipação do homem em relação à servidão de seu ambiente. [...]” (CHILDE, 1975, p. 62), pois seu domínio “[...] marcou uma mudança substantiva, sendo utilizado para o aquecimento, para a defesa e o ataque, para cozinhar os alimentos e endurecer a madeira das armas e das ferramentas, entre outras tantas alternativas que foram sendo gradativamente descobertas" (FOLADORI et all, 2016, p. 19).

No ato de produzir a vida material está o ato de fabricar os meios de produção, o que torna o homem um produtor de ferramentas como extensão do seu corpo, como meio de auxiliá-lo na transformação da natureza. Nesta perspectiva, Childe assegura que "o aparecimento do homem sobre a Terra é indicado pelos instrumentos que ele fez", posto que "o homem necessita de instrumentos para 
suplementar as deficiências de seu equipamento fisiológico na obtenção de alimento e abrigo". [...] (CHILDE, 1975, p. 61). Neste ato, o conhecimento gerado na produção de instrumentos ganha significado e importância vital à vida do homem, porque cada novo equipamento agrega novos conhecimentos aos já acumulados no devir histórico do homem. Por isso, Andery et all apontam que cada ato de produção da vida cria uma nova interação e, com ela, reflete uma natureza modificada. Com isso, os homens incorporam criações antes inexistentes ao processo de reflexão e, neste processo, já encontram também um homem modificado frente a natureza, cujo trabalho vai forjando no homem sua consciência "[...] pois suas necessidades, condições e caminhos para satisfazê-las são outros que foram sendo construídos pelo próprio homem. É nesse processo que o homem adquire consciência de que está transformando a natureza para adaptá-la a suas necessidades [...]", pois a ação humana "é intencional e planejada; em outras palavras, o homem sabe que sabe" (ANDERY et all, 1994, p. 13). Dessa forma, Schaff (1969, p. 85-86) traz que "[...] do ponto de vista do homem, o processo humano de criação é um processo de auto criação. Assim, graças ao trabalho a espécie Homo-sapiens nasceu, evoluiu e continua a transformar-se". Portanto, o ato de produzir a vida do homem se torna um ato consciente e intencional, de interesse coletivo, pois o homem não vive isolado, ele depende de outros para sobreviver. Neste processo, ele se transforma em um ser social.

É sobre está perspectiva que o estudo dará materialidade ao artigo.

\section{E o verbo se fez carne}

O Homo erectus foi a primeira espécie humana a utilizar o fogo; a primeira a incluir a caça como parte significativa de sua subsistência; a primeira capaz de correr como os humanos modernos o fazem; a primeira a fabricar instrumentos de pedra de acordo com um padrão definido; a primeira a estender seus domínios para além da África (LEAKEY, 1997, p. 13).

$\mathrm{Na}$ luta pela vida, vencer os imperativos dados pelas forças da natureza é imprescindível à hominização. Este processo não é estabelecido pela palavra de um Deus, mas da ação imposta à luta pela sobrevivência de grupos de hominídeos, que vão forjando uma unidade na luta pela vida e na defesa do grupo, pois o ato de comer, beber, vestir e abrigar exige do grupo social uma vida comum. Este ato contínuo de luta pela vida é um ato de produção da existência material como comunidade humana, pois "na história humana, as roupas, ferramentas, armas e tradições tomam o lugar das peles, garras, presas e instintos na busca de alimentos e abrigos" e, no decurso da vida, "o homem aprende métodos mais eficientes e discriminativos de obter alimento, através do preceito e exemplo de seus mais velhos" (CHILDE, 1975, p. 32). Mas como o homem aprende? Ele se solta dos instintos naturais, inerente ao muno animal, e aprende pelo processo do trabalho. Pelo trabalho, diz Vieira Pinto, “[...] o homem instrumentaliza os objetos que lhe são amanuais e os transforma em recursos para a ação sobre a natureza. [...] (VIEIRA PINTO, 1969, p. 340). O trabalho é o diferencial entre o homem e os animais, pois o ato de trabalho se constitui em um comportamento verdadeiramente humano e isto o leva a realizar experiências na fabricação de ferramentas como meio de expandir suas forças físicas para agir na natureza. No homem, a experiência assume um caráter de desenvolvimento histórico, pois “[...] torna-se fonte de atos originais concebidos primeiramente 
como plano do pensamento e depois executados na prática da existência, [...]” (VIEIRA PINTO, 1969, p. 342). Não é sem razão que Vieira Pinto (1969, p. 342) sustenta que

[...] Com efeito, somente na tentativa humana a ação se torna fonte de ideias, e por isso representa um modo de experimentar, de palpar, de descobrir aquilo que consiste o mundo, quais são as propriedades das coisas, que, ao se transformarem em conceitos abstratos, permitem o retorno do pensamento à realidade em forma de projetos de ação, e portanto em processo de melhoramento da relação do homem com o mundo, o que é propriamente o trabalho.

Neste processo, Engels demonstra que o trabalho e a fabricação de diferentes ferramentas necessárias à reprodução da vida constituíram-se na peça chave para o processo de transição do macaco ao homem. Um devir lento que incluía, dentre outros elementos, certas características físicas, como a mão, a fala e o próprio cérebro.

Em seus estudos, Engels (1952, s/p) assevera que

[...] as funções, para as quais nossos antepassados foram adaptando pouco a pouco suas mãos durante os muitos milhares de anos em que se prolongam o período de transição do macaco ao homem, só puderam ser, a princípio, funções sumamente simples. Os selvagens mais primitivos, inclusive aqueles nos quais se pode presumir o retorno a um estado mais próximo da animalidade, com uma degeneração física simultânea, são muito superiores àqueles seres do período de transição. Antes de a primeira lasca de sílex ter sido transformada em machado pela mão do homem, deve ter sido transcorrido um período de tempo tão largo que, em comparação com ele, o período histórico por nós conhecido torna-se insignificante. Mas já havia sido dado o passo decisivo: a mão era livre e podia agora adquirir cada vez mais destreza e habilidade; e essa maior flexibilidade adquirida transmitia-se por herança e aumentava de geração em geração.

Neste aspecto, o afastamento da barreira natural vai criando as bases de hominização, cuja centralidade reside no ato circunscrito de produzir a existência da vida material e, ao mesmo tempo, na emancipação do homem frente ao seu ambiente por meio do controle do fogo. No processo do afastamento do meio natural, o domínio do fogo é o domínio de uma das forças da natureza, que permite ao longo do devir humano ganhos materiais no processo de humanização, pois lhes assegura experiências constante na utilização do fogo, como proteção contra outros animais, na alimentação e na fabricação de instrumentos de caça, habitação e vestimenta.

Não obstante, Childe (1975, p. 63) sustenta que

Ao dominar o fogo, o homem estava controlando uma poderosa força física e uma notável transformação química. Pela primeira vez na história, uma criatura da Natureza dirigia uma das grandes forças naturais. E o exercício do poder deve reagir sobre quem o exerce. A visão de uma chama crepitante, elevando-se do galho seco era lançada entre as brasas brilhantes, a transformação do galho em cinzas finas e fumaça, deve ter estimulado o cérebro rudimentar do homem. Impossível saber o que lhe sugeriam tais fenômenos. Mas ao alimentar ou apagar o fogo, ao transportá-lo e usá-lo, o homem afastou-se revolucionariamente do comportamento dos outros animais. Afirmou sua humanidade e se fez homem.

Na luta pela vida, o domínio e o controle sobre o fogo são elos também de unificação social do grupo de hominídeos, pois dele emanava um poder sobre a natureza e lhes permitiam modelar objeto de acordo com suas necessidades e interesses imediatos. Na defesa à vida, o hominídeo vai desenvolvendo em si mesmo habilidades de observação, criação e de domínio sobre a natureza. Pela observação de outros animais, permitiu compreender que os membros do corpo eram extensões naturais que poderiam servir de 
imediato à vida. Das mãos, poderiam coletar frutos, colher água para beber, atirar pedras para autodefesa e construir ferramentas como extensão do próprio corpo, a princípio básica, mas fundamental para vencer as barreiras iniciais da produção da vida, como o machado de pedra e a lança. Ou seja, vai incorporando e desenvolvendo atividade constante, que lhe permite produzir a existência material e ganhar mobilidade cada vez mais consciente sobre o espaço que habita. Mas a "atividade é uma unidade não-aditiva da vida material, corpórea, do sujeito material. [...] no plano psicológico, é uma unidade de vida, mediada pela reflexão mental, por uma imagem, cuja função real é orientar o sujeito no mundo objetivo" (LIONTIEV, 1972, p. 02). Isso significa que a atividade mediada pelo trabalho lhe permite construir objetos à produção e à defesa da vida de forma contínua, mas encorpando novos conhecimentos adquiridos na atividade produtiva frente as novas realidades encontradas no devir histórico. No processo da existência da vida, os equipamentos e as defesas dos homens, que são exteriores ao seu corpo, podem ser colocados de lado ou utilizados, segundo sua vontade. Porém, sua construção e utilização não é herdada, mas aprendida, de forma lenta, com o grupo social a que o indivíduo pertence (CHILDE, 1975, p. 33). Ou seja, na produção da vida se acumula conhecimento sobre os atos produtivos e desenvolve o processo de aprendizagem, pois a produção passa a ser um ato intencional, um ato do pensamento materializado para a preservação da vida e elo de reprodução social. A educação nasce nesse processo, cujo princípio e ensinar à geração posterior o que se sabe sobre a fabricação de equipamentos, os métodos de caça, de defesa da vida etc.

$$
\text { Não obstante, Vieira Pinto (1969, p. 340) afirmara }
$$

[...] O trabalho só se tornou possível porque o processo de evolução biológica levou a espécie que seria mais tarde a do 'homo sapiens' a produzir e desenvolver em forma de processo histórico instrumentos materiais que lhe permitiram modificar o meio ambiente em função de finalidades, que, sendo ideias na esfera do pensamento, se foram aos poucos criando e tornando conscientes. A produção das ideias e dos instrumentos são duas faces do mesmo processo acumulativo, entre as quais se trava um determinismo recíproco. A princípio os instrumentos são os próprios membros, especialmente as mãos e os dedos que, libertados da obrigação de apoiar a marcha, se tornam expedidos para tarefas mais delicadas. Mas não é apenas a destreza manual, aumentada pela oposição do polegar aos restantes dedos, que explica esse progresso, porque também em algumas espécies antropóides, particularmente nos pongídeos, estas particularidades anatômicas se verificam, sem que os animais desse tipo se tornem capazes de realizar efetivo trabalho. É que no homem em formação, concomitantemente com a especialização sensorial e motora dos membros superiores, dava-se outra evolução anatômica que levaria a constituir-se em ser capaz de trabalhar: trata-se do processo de cefalização, a que se refere Tailhard de Chardin, e que no homem culmina na complexidade histológica e nas reações bioquímicas da substância cinzenta do cérebro, em virtude das quais se torna possível uma escala de reflexos condicionados que terminam no surgimento da ideia abstrata. Quando esta etapa é atingida, embora não se possa assinalar nenhum momento de transição brusca, nem datar cronologicamente o começo dessa fase, o homem entra realmente a trabalhar, porque não só as operações elementares que já anteriormente fazia, muitas das quais eram comuns a ele e aos antropoides, passam a ser feitas agora em função de uma percepção ideativa e não mais instintiva, como se abre para a ação um espaço de infinitas oportunidades, com a descoberta fundamental, que em tal fase consegue fazer, a descoberta da instrumentalidade dos objetos naturais, dispostos aí, ao alcance da mão, e como sinal supremo da passagem à era hominídea a capacidade de fabricá-los intencionalmente. [...].

Neste processo, "[...] o homem primitivo teve de aprender gradualmente, pela experiência, quais as pedras mais adequadas à manufatura de ferramentas, e como lascá-las corretamente" (CHILDE, 1975, p. 62), ou seja, desde os primórdios da humanidade o homem se torna força de trabalho no processo de 
produção da vida e, com isso, ele desenvolve a ciência no processo de criação de ferramentas necessárias à vida. Portanto, da ideação à fabricação dos instrumentos de trabalho, o homem produz de forma consciente o que necessita para agir sobre a natureza. Mas para que ele passa fazê-lo, ele necessita conhecê-la e, para tanto, está obrigado a investigá-la. Neste processo, Vieira Pinto sustenta que “[...] a atividade investigadora acha-se, pois, na origem da relação do homem com o mundo, a qual não tem um caráter passivo, como nos animais que formam e transmitem hereditariamente atos instintivos". Dessa forma, o homem "[...] adaptase ativamente à natureza, pelo ato de adaptá-la a ele. Mas, para tanto faz-se preciso conhecer as propriedades dos corpos que compõem o mundo, as leis que os regem", por isso, "o sujeito deve apoderar-se em forma de ideias de tais dados objetivos para com eles organizar o projeto de transformação da realidade" (VIEIRA PINTO, 1969, p. 374). Neste sentido, “[...] as ideias são a expressão das relações e atividades reais do homem, estabelecidas no processo de produção de sua existência. Elas são a representação daquilo que o homem faz, da sua maneira de viver", portanto, “da forma como se relaciona com outros homens, do mundo que o circunda e das próprias necessidades". [...] (ANDERY et all, 2004, p. 14). Neste campo de entendimento, Schaff (1969, p. 82) sustenta que o homem é um produto social, "e na sua ontogênese, está completamente submetido ao determinismo social que o forma, num modo que escapa do seu controle, por via da língua que tem em si um determinado sistema de pensamento, da educação que lhes inculca hábitos, costumes, comportamentos definidos, etc [...]”.

Nesta perspectiva, Marx (1983, p. 149) escreveu que

[...] o trabalho é um processo entre o homem e a Natureza, um processo em que o homem, por sua própria ação, media, regula e controla seu metabolismo com a Natureza. Ele mesmo se defronta com a matéria natural como uma força natural. Ele põe em movimento as forças naturais pertencentes a sua corporalidade, braços e pernas, cabeça e mão, a fim de apropriar-se da matéria natural numa forma útil para sua própria vida. Ao atuar, por meio desse movimento, sobre a Natureza externa a ele e ao modificá-la, ele modifica, ao mesmo tempo, sua própria natureza. [...].

Neste sentido, Marx afirma que o trabalho dá forma ao homem e o coloca em pé frente a natureza para produzir sua própria vida material. No ato do trabalho ele move e transforma a natureza para si e, com isso ele também se transforma. O caráter mutuo da transformação (homem/natureza), determina o conjunto da vida humana de forma perene, mas em constante transformação sócio-histórica no campo das determinações históricas e das necessidades humanas a serem satisfeitas.

Estudando Marx, Serpa (2014, p. 28) sustenta que

[...] O trabalho, ao mesmo tempo em que se configura como relação histórica entre homem e natureza, determina o conjunto da vida humana. A apropriação da natureza pelo homem, na satisfação de suas necessidades mais básicas e elementares, só se efetiva através da mediação do trabalho, da atividade produtiva mesma. Estas necessidades primárias (ou 'naturais'), ao serem satisfeitas, possibilitam a criação de outras - estas cada vez mais necessidades puramente sociais. Ou seja, o trabalho, como mediador, engendra a transformação da natureza - no sentido de sua progressiva sociabilização - ao mesmo em tempo que transforma o próprio homem, tornando o gênero humano cada vez mais um gênero para si - constituindo-se como plataforma do infinito processo de humanização do homem, em escala progressiva e potencialmente mais ampla e complexa.

O trabalho é, portanto, a peça chave na hominização. Na atividade do trabalho o homem se hominiza à medida em age sobre a natureza adaptando-a para si. O trabalho é o parto que se dá na esfera 
do hominídeo e a natureza, o qual "permite tentar diminuir as consequências negativas das intempéries do meio ou suprir necessidades vitais, como comer ou se proteger do frio" (SILVA, 2008, s/p). Na observância da natureza, Engels sustenta que os animais podem utilizar e modificar a natureza em virtude de sua presença nela, mas "[...] o homem, ao contrário, modifica a natureza e a obriga a servir-lhe, domina-a. E aí está, em última análise, a diferença essencial entre o homem e os demais animais, diferença que, mais uma vez, resulta do trabalho" (ENGELS, 1952, s/p). Dessa forma, o trabalho afasta o hominídeo da barreira natural em que se encontrava frente a natureza e dá materialidade ao homem e ao ser social. O verbo se torna carne, mas se torna carne pelo trabalho.

\section{A dimensão ontológica do ser social}

[...] Toda realidade material perdura, manifestando no tempo alguma modalidade essencial da sua constituição objetiva. No homem essa modalidade adquire significado novo, qualitativamente distinto, o da historicidade. Ao viver, o homem historiciza o tempo, a duração cronológica do existir da realidade. [...] (VIEIRA PINTO, 1969, p. 188).

No devir histórico da humanidade, o trabalho foi o motor explosivo da vida humana. Ao relacionar-se de forma objetiva com a natureza, o homem se torna uma ferramenta de domínio da natureza para criar as bases que lhes permite comer, beber, vestir-se, tem abrigo e segurança no cotidiano da vida. Tem uma vida determinada pelo trabalho, que o obriga a supri-la todos os dias de forma constante. Neste processo de afastamento da barreira natural feito pelo homem em sua luta pela vida, o fato determinante são as relações sociais por ele criadas no devir histórico, determinando o tipo de formação social e de cultura material. Neste sentido, Marx (1983, p. 153) assegura que “[...] o processo de trabalho, como o apresentamos em seus elementos simples e abstratos, é atividade orientada a um fim para produzir valores de uso, apropriação do natural para satisfazer a necessidades humanas, condição universal do metabolismo entre o homem e a Natureza" e esta é uma "condição natural eterna da vida humana e, portanto, independente de qualquer forma dessa vida, sendo antes igualmente comum a todas as suas formas sociais". Mas o trabalho, como ato pensado pelo homem, não é só a transformação da natureza na criação de valores de usos. Traz também a dimensão social das formações históricas impressas na história da vida do homem, cujas características estão dadas pelas relações de trabalho estabelecidas em âmbito social. Em sua dimensão ontológica, o homem reproduz sua existência material nas condições dadas e encontradas na natureza e, ao fazê-la, ele se adapta à natureza em todas as suas dimensões, quer sejam naturais, quer sejam sociais. Ao adaptar a natureza para si, o homem cria uma cultura material que lhe permite criar códigos a serem transmitidos de forma contínua e permanente entre o grupo social. Este fato assegura a sobrevivência do grupo social, cuja dimensão é dada pela forma e relação de trabalho estabelecida socialmente. Neste aspecto, a luta pela vida de fato é um elo que liga os indivíduos e os tornam sujeitos coletivos, pois estabelecem laços sociais para além da mera luta pela sobrevivência e constroem identidades de grupo e formas de expressão cultural, como a linguagem no processo de identificação de objetos, a produção de moradia, a criação artística e o nascimento da religião. Não obstante, Foladori et all (2016, p. 15) afirmam que "a linguagem 
como expressão do pensamento, a religião, as artes e as complexas formas de organização social se desenvolveram como resultado do trabalho, de sua diversificação e aperfeiçoamento”.

Na luta contínua pela sobrevivência por meio da busca por alimentação, habitação, vestimentas, etc, acumularam conhecimento dos atos praticados e desenvolveram formas de transmitir à geração mais nova aquilo que sabem. Neste processo, passam a representar as cenas de caça de animais, de formas de animais etc, em imagens desenhadas nas paredes das cavernas, que servem para ensinar aos mais jovens as estratégias e as táticas nas lutas pela sobrevivência. Para esse fim, Childe (1975, p. 74) sustenta que “[...] a representação de animais, imitados fielmente em todas as posições naturais, só podia ser feita por homens que os tivessem estudados de perto em seu ambiente nativo, como o faz o caçador". Além disso, desenvolveram e aprimoraram o uso da linguagem como comunicação e constrói seus deuses como sinal de ligação à vida. No devir histórico, constroem, a partir do trabalho, métodos educacionais para a reprodução da vida material e espiritual da vida em sociedade. Dessa forma, ao produzir a vida material de forma coletiva o homem produz também a vida social. Isto é, se organiza de forma produtiva e social, o que implica em dizer que o homem cria uma sociedade, cria o mundo humano e as relações sociais dadas pela forma de trabalho. Nesta perspectiva, Braveman (1987, p. 29) afirma que "[...] os determinantes sociais não possuem a fixidez de uma reação química, mas são um processo histórico" e que "as formas concretas e determinadas de sociedade são, de fato 'determinadas', e não acidentais, mas se trata do determinante da tecelagem fio por fio da tessitura da História, jamais a imposição de fórmulas externas”. Para tanto, a premissa básica da vida do indivíduo é uma vida em sociedade, sem a qual não há humanidade "ou melhor ainda a 'essência do homem' é, pois reconduzido ao papel de uma função das relações sociais" (SCHAFF, 1969, p.81).

Nesta perspectiva, Einsten (1949, s/p) observa que

O conceito abstrato de 'sociedade' significa para o ser humano individual o conjunto das suas relações diretas e indiretas com os seus contemporâneos e com todas as pessoas de gerações anteriores. O indivíduo é capaz de pensar, sentir, lutar e trabalhar sozinho, mas depende tanto da sociedade - na sua existência física, intelectual e emocional - que é impossível pensar nele, ou compreendê-lo, fora da estrutura da sociedade. É a 'sociedade' que lhe fornece comida, roupa, casa, instrumentos de trabalho, língua, formas de pensamento, e a maior parte do conteúdo do pensamento; a sua vida foi tornada possível através do trabalho e da concretização dos muitos milhões passados e presentes que estão todos escondidos atrás da pequena palavra 'sociedade'.

$\mathrm{Na}$ luta constante pela sobrevivência da vida social, o homem afirma seu caráter humano no devir histórico do trabalho. Ao fazê-lo, a forma trabalho adquire uma dimensão social peculiar, sob o qual uma determinada classe a captura para si, alienando-o para que seja executado por outra classe. Este ato assegura um domínio de classe sob o trabalho na perspectiva histórica das dimensões ontológicas do ser social, pois “o homem nasce em uma sociedade definida, em condições e relações sociais e humanas determinadas que ele não escolhe mas que lhe são dadas como resultado da atividade das gerações precedentes" (SCHAFF, 1969, p. 82). Com efeito, Bezerra Neto (2009, p. 3) afirmara

[...] Considere-se que em qualquer sociedade o homem é necessariamente levado a pensar de acordo com o modo de produção desenvolvido no momento em que ele está vivendo, pois a maneira como nos organizamos para produzir a nossa sobrevivência 
determina nossa forma de pensar e agir socialmente, fazendo com que nos tornemos seres situados no tempo e no espaço. [...].

O fato determinante neste processo está a organização social do trabalho, que foram desenvolvidas pelos homens no decurso da humanidade. Neste processo, o modo de produzir a vida material condiciona a vida social. Este fato foi constatado por Marx e Engels quando estavam escrevendo A Ideologia Alemã. Segundo eles,

A forma como os homens produzem esses meios depende em primeiro lugar da natureza, isto é, dos meios de existência já elaborados e que lhes é necessário reproduzir; mas não deveremos considerar esse modo de produção deste único ponto de vista, isto é, enquanto mera reprodução da existência física dos indivíduos. Pelo contrário, já constitui um modo determinado de atividade de tais indivíduos, uma forma determinada de manifestar a sua vida, um modo de vida determinado. A forma como os indivíduos manifestam a sua vida reflete muito exatamente aquilo que são. $O$ que são coincide portanto com a sua produção, isto é, tanto com aquilo que produzem como com a forma como produzem. Aquilo que os indivíduos são depende portanto das condições materiais da sua produção (MARX; ENGELS, 1980, p. 18).

O fato arguido por Marx e Engels é que a vida social é determinada pela forma de produção. Em outras palavras, a maneira de como o homem produz os bens necessários à vida determina a forma de relação social do trabalho. E esta forma de produzir não é inerte, ela se move como se move a sociedade. Ela se move em um processo dialético, em permanente transformação e, neste processo, as formas de produzir também são transformadas com os homens, os quais se submetem às mudanças na base produtiva e isto ocorre independentemente de sua vontade pessoal, gerando novos conhecimentos, criando novos costumes e valores éticos e morais presentes em cada formação social. Nesta perspectiva, Andery et all (1994, p. 13) asseguram que “o processo de produção da existência humana é um processo social; o ser humano não vive isoladamente, ao contrário, depende de outros para sobreviver" e nela "há interdependência dos seres humanos em todas as formas da atividade humana; quaisquer que sejam suas necessidades — da produção de bens à elaboração de conhecimentos, costumes, valores. [...] —, elas são criadas, atendidas e transformadas a partir da organização e do estabelecimento de relações entre homens". Ou seja, “[...] a forma de qualquer sociedade, não é criação instantânea de 'leis' que geram aquela sociedade num lugar e diante de nossos olhos. Toda sociedade é um momento no processo histórico, e só pode ser aprendida como parte daquele processo. [...]" (BRAVERMAN, 1987, p. 29).

Não obstante, Foladori et all (2016, p. 18) trazem que

Assim como o trabalho direcionado à acumulação de instrumentos e objetos distinguiu os homens dos animais, as formas de trabalho permitem explicar as etapas econômicas da sociedade e sua dinâmica. Chamamos forma do trabalho ou relação de produção o tipo de relações que se estabelecem entre os homens ao produzir os bens materiais. Ainda quando é possível encontrar, em qualquer etapa histórica, variadas formas de trabalho, uma delas sempre se sobrepõe às demais em termos de generalizações e de importância. Cada forma histórica de trabalho encontra correspondência em certo nível de desenvolvimento técnico e científico; também correspondem, ainda que de uma maneira muito mais irregular e distanciada, as formas de organização política e inclusive expressões religiosas e artísticas. [...].

Apenas destacamos a afirmação de Foladori et all de que há formas históricas de organização da produção da vida material e que as formas de trabalho explicam as relações sociais 
de trabalho e as tendências de sua transformação no interior de cada formação social, que os homens edificaram no seu devir histórico (comunidade primitiva, comunidade agrária excedentária, tributo coletivo, escravismo, feudalismo, capitalismo etc), mas isso não faz parte do presente estudo.

\section{Conclusão}

A existência do homem no mundo se explica por meio da atividade exercida pelo hominídeo na natureza em meio à luta pela vida. Essa atividade é o trabalho. Nesta atividade, o passo fundante foi a libertação das mãos, as quais foram, sem dúvida, o primeiro meio de trabalho criado pelo homem. Ou seja, ele passa a usar de seus próprios membros (mãos, braços e pernas) como meio necessário à produção de bens necessários à vida, incluindo, a posteriori, a fabricação de ferramentas e a acumulação de objetos, o que acaba distinguindo-o dos animais. Liberadas as mãos, no seu longo processo de evolução, o hominídeo se faz homem e cria o mundo humano. Ao criar o mundo humano, ele cria a vida social, cuja centralidade dada é a vida coletiva mediada pelo trabalho na produção da existência da vida e, com isso, ele desenvolve uma linguagem comum ao grupo para facilitar a comunicação na vida social. Ele cria a arte para representar a vida e, por isso estuda a natureza em que vive. Cria também suas representações religiosas e as formas de organizar a vida social por meio da política, cria o Estado.

$\mathrm{Na}$ existência da vida humana sobre a terra, o trabalho funda o ser social e, sob como se organiza a produção da vida social, ele cria uma determinada formação social, sob o qual o produto do trabalho é expropriado por homens que se afastam da atividade do trabalho. Neste devir histórico, o homem criou vários tipos de formações humanas e a divisão da sociedade em classe dominante (dona dos meios de trabalho) e a classe dominada (tem o trabalho expropriado).

Neste devir, portanto, a luta pela vida feita pelos hominídeos se faz o homem e, com ele, a humanidade presente em cada formação social.

\section{Referências bibliográficas}

ANDERY, Maria Amália Pie Abib; et all. Para compreender a ciência: uma perspectiva histórica. $5^{a}$ Ed. Rio de Janeiro: Espaço e Tempo, 1994.

BEZERRA NETO, Luiz. Sem-Terra aprende e ensina: estudo sobre as práticas educativas do movimento dos trabalhadores rurais. Campinas, SP: Autores Associados, 1999.

BRAVERMAN, Harry. Trabalho e capital monopolista: a degradação do trabalho no Século XX. $3^{a}$ Ed. Rio de Janeiro: Editora Guanabara, 1987.

CHILDE, V. Gordon. A evolução cultural do homem. 3ª Ed. Rio de Janeiro: Zahar Editores, 1975.

EINSTEIN, Albert. Por que socialismo? Maio de 1949. Traduzido por Ralf Rickli. In.

https://www.marxists.org/portugues/einstein/1949/05/socialismo.htm. Acessado em 15/05/2014.

ENGELS, Friederich. O Papel do Trabalho na Transformação do Macaco em Homem. Da edição Soviética de 1952. In https://www.marxists.org/portugues/marx/1876/mes/macaco.htm. Acessado em 17/03/2013. 
FOLADORI, Guillermo et all. A economia da sociedade capitalista e suas crises recorrentes. São Paulo: Outras Expressões, 2016.

FRIGOT'TO, Gaudêncio. A dupla face do trabalho: criação e destruição da vida. In. A Experiência do trabalho e a educação básica. $3^{\text {a }}$ ed. Rio de Janeiro: Lamparina, 2010.

LIONTIEV, Alexei Nikolaevich. Atividade e Consciência. 1972. Tradução do inglês: Marcelo José de Souza e Silva. In. https://www.marxists.org/portugues/leontiev/1972/mes/atividade.htm. Acessado em 19/05/2014.

LEAKEY, Richard. A origem da espécie humana. Rio de Janeiro: Rocco, 1997.

LUKÁCS, Gyorgy. Para uma ontologia do ser social I. São Paulo: Boitempo, 2013.

MARX, K.; ENGELS, F. A Ideologia Alemã: crítica da filosofia alemã mais recente na pessoa dos seus representantes Feuerbach, B. Bauer e Stirnes, e do socialismo alemão na dos seus diferentes profetas. Lisboa: Presença; Martins Fontes, 1980. v. 1-2.

O capital. V. I, tomo 1. São Paulo: Abril Cultural, 1983.

PARO, Vitor Henrique. Parem de preparar para o trabalho!!! Reflexões acerca dos efeitos do neoliberalismo sobre a gestão e o papel da escola básica. In. Trabalho, formação e currículo: para onde vai a escola? Org. Celso João Ferretti et alii. São Paulo: Xamã. 1999.

SCHAFF, Adam. A Concepção Marxista do Indivíduo. IN: VOLPE, Della (org.). Moral e Sociedade. Rio de Janeiro: Paz e Terra, 1969.

SERPA, Paola Baldovinotti. Marx (1843-1852): política e revolução - um (re)encontro com a emancipação do trabalho. (Tese de doutorado). UNESP - Marilia, 2014.

SILVA, Michel. O macaco e o trabalho. In. Revista Urutágua. No 14 - dez. 07/jan./fev./mar. 2008 Quadrimestral - Maringá - Paraná - Brasil.

VIEIRA PINTO, Álvaro. Ciência e existência: problemas filosóficos da pesquisa científica. Rio de Janeiro: Paz e Terra, 1969.

\footnotetext{
1 Universidade Estadual do Paraná - Campus de Paranavaí. Prof. Adjunto do Colégiado de História, área de atuação em História Medieval, História Econômica, Educação do Campo e Escola Intinerante do MST. Dr em Educação pela UFSCar. ORCID: http://orcid.org/0000-0002-7698-4064 Email: vanderlei.amboni@unespar.edu.br
} 